\title{
Sustainable Urban Development in the Context of Globalization and the Health Crisis Caused by the Covid-19 Pandemic
}

\author{
Roxana Sarbu ${ }^{1}$, Cristina Alpopi ${ }^{1}$, Sorin Burlacu ${ }^{1 *}$ and Silviu Diaconu ${ }^{1}$ \\ ${ }^{1}$ Bucharest University of Economic Studies, 6 Piata Romana, Bucharest Romania
}

\begin{abstract}
Research background: The concept of sustainable development had as its starting point the global ecological crisis 1929-1933 and was later developed by encompassing all economic and social and human spheres, reaching that today, sustainable development is the new path of humanity. Sustainable development has been conceived as a solution to the ecological crisis determined by the intense industrial exploitation of resources and the continuous degradation of the environment and seeks first of all to preserve the quality of the environment. Sustainable development promotes the concept of reconciling economic and social progress without endangering the natural balance of the planet.

Purpose of the article: The objective of this paper is to highlight the trends determined by the current health crisis.

Methods: The main research method is the bibliographic study doubled by a secondary documentary analysis that allowed us to identify both the historical evolution of the concept and the detachment of current trends.

Findings \& Value added: All these concepts take on a new meaning in the current pandemic context and the trend seems to be man's return to nature and villages, perhaps determined by home isolation as the central method imposed by most countries in the fight against Coronavirus.
\end{abstract}

Keywords: sustainable urban development; health crisis; globalization

JEL Classification: $Q 01 ; O 18 ; H 12$

\footnotetext{
* Corresponding author: sburlacu@amp.ase.ro
} 


\section{Introduction}

Sustainable urban development requires changes in governance, market and regulation for both cities and nations and for the environment [1]. Achieving the goal of urban sustainability is perhaps one of the most pressing issues facing planners and governments [2]. We also support research that argues that urban areas, especially cities, are significant consumers of materials and energy. These consumptions can be made both directly on their land surfaces and indirectly through the materials, goods and services they import or export [3].

The United Nations reports and considers that urban areas are the zero zone of the COVID-19 pandemic, with $90 \%$ of cases reported as cities brutally facing the crisis with tense health systems, inadequate water and sanitation services and other challenges, especially in areas poorer, where the pandemic has exposed deep-rooted inequalities. The objectives of sustainable development of human settlements are related to controlling the evolution of urban space, in order to build a more balanced system, especially monitoring the dynamics of urban growth, mitigating spatial and social segregation especially in large cities, environmental and transport problems. In fact, a city is perhaps the most dramatic manifestation of human activities on the environment. Studies of all times show that this man-made and human-dominated organism degrades natural habitats, simplifies species composition, disrupts hydrological systems, and alters the flow of energy and the nutrient cycle. In this context, sustainable urban development (SUD) is seen as a panacea that would minimize the effects caused by large-scale human activities on the environment $[4,5]$. In fact, we agree that a city, especially today, needs to know when to grow and how to grow [6].

\section{Literature review}

The concept of sustainable development had as its starting point the global ecological crisis 1929-1933 and was later developed by encompassing all economic and social and human spheres, reaching that today, sustainable development is the new path of humanity. Sustainable development has been conceived as a solution to the ecological crisis determined by the intense industrial exploitation of resources and the continuous degradation of the environment and seeks first of all to preserve the quality of the environment. Sustainable development promotes the concept of reconciling economic and social progress without endangering the natural balance of the planet. The term habitat, in the context of urban planning and local development activities, defines the framework and living conditions of a population / community in general, the way of structuring / organizing human settlements, as well as, especially in the case of cities, the part of a specially built tissue, intended for housing, whether or not associated with other urban functions. The technical term habitat (fr. Habitat; engl. Housing) corresponds to the notion of living in Romanian [7]. Housing is a concept that, based on housing, involves a complex set of needs and socio-economic activities directly or indirectly related to housing, such as: infrastructure (networks, roads), urban facilities and social services (education, health, culture, trade, transport, leisure), characteristics and quality of housing (degree of endowment, structure and degree of occupancy, maintenance costs, neighborhoods), environment [8].

One of the fundamental conditions for the existence of the human population is to live. Dwelling is the process of complex coexistence of human communities in settlements (localities), in interrelationships with the natural and man-made environment. It is the 
fundamental factor of harmony, social stability and quality of life of the human population, being the key element of the development of human settlements [9]. Housing is an important part of national wealth and is a measure of social welfare, as well as an incentive for economy and investment. The phenomenon of habitation is defined not only by its spatial and technological dimension [10]. It is the product of complex relations of a social, economic and cultural nature, all circumscribed by historical coordinates and related to the territory [11]. In addition, housing is determined by the spatial and functional relationships it establishes with the network of public facilities, which it incorporates (including service networks and municipal networks) [12].

Dwelling comprises a whole structure of constituent elements (having the dwelling in the central area of concern) and is the result of a whole series of determinations that exceed the strict limits of the physical and spatial framework [13].

A structured analysis of housing must take into account the social, political, administrative and legislative framework, elements of psycho-sociological context (behavioral framework), the conceptual framework, defined by cultural models existing at a certain historical moment, and in the field of material manifestations in the field of living (interfering with the determinations related to the natural environment, the built one, as well as the conditions resulting from the technical-economic field of constructions).

The way of living is the result of the mutual influences of the areas listed above. The quality of housing is determined by all these factors, the results being analyzable sociologically in terms of: design, image, comfort and safety of housing.

The particular case of urban housing is the result of complex socio-economic functions at group and individual level that take place in the city [14]. The urban quality consists in the degree of comfort that benefits the population of the city, higher than in the rest of the territory, as a result of the level of complex equipment of these settlements [15].

The urban dwelling is differentiated from the rural one from a functional point of view by its integration in the urban functional structures, at the level of the respective human settlement and of the residential ensemble; the houses, endowments and arrangements that make up the residential framework are in dynamic relations of interdependence with the systems of economic, psycho-social, institutional and cultural structures of the city [16]. In this case, the housing integration processes aim at translating some of the housing functions to functional structures (constructions and institutions) developed in the urban territory.

"Housing is part of the category of major problems of humanity, related to social and economic development, of importance close to those of food and health, environment and energy. It has a global and permanent character, its solution being a problem open to the entire population in the succession of generations" [17].

Adding to this the fact that housing involves the connection between housing, technicalmunicipal and socio-cultural facilities for a single purpose, that of satisfying the preferences and aspirations of community members, can determine the scope of housing.

The housing problems, therefore, no longer have a functional and utilitarian character, but also a pronounced social and political character. In the contemporary period, the concentration of the population in cities requires the establishment of mandatory norms on hygiene, functionality and safety requirements for buildings. These conditions make it impossible for individuals and families to solve the housing problem by each generation. Cooperation between individuals, to which is added the intervention of public force, becomes the only means by which operational solutions can be found for such a difficult problem and, moreover, in the process of amplification, due to the rapid pace of urbanization.

Given that the house is located in certain natural conditions, the study of the land in all its aspects is another main factor of the sphere of living [18]. They are also considered as the main factors of housing: climate, water and energy supply, the existence of utilities and 
waste disposal spaces, relaxation areas, commercial areas, parking lots. Natural conditions have always been the primary element in the development of society. They can be differentiated into two main categories:

- natural resources, in the form of means of subsistence (soil fertility, water, air, fauna, flora);

- natural resources, in means of work such as minerals, fuels, energy (hydraulic, wind, nuclear) that have contributed to the achievement of a differentiated housing in terms of performance.

Having succeeded in influencing nature, the man of the 21 st century is inclined to disregard the sometimes-brutal revenge that nature could often take. Water and air pollution, massive deforestation, unbearable noises, the consequences of aggressive urbanization, as well as excessive use of food substitutes, increasingly difficult disposal of urban waste are the result of a greedy industrialization, an absolute contempt for human health [19].

The mass exodus of urbanites from all over the world every weekend and to some extent even every evening to the cleaner air areas is the most telling sign of a lowperforming urban dwelling. It can be said that man's interaction with the natural environment has reached extreme forms, posing a danger to the very biological existence of mankind, as a result of the depletion of natural sources and pollution, harmful to human life and its environment [20]. To continue an unaltered life of disruptive factors, the concept of "sustainable development" was created by the global approach to development as a dynamic process that evolves over time and comprehensively involving the whole Earth [21]. The notion introduced in 1972 at the World Environment Conference in Stockholm under the name of eco-development has been repeated in various forums of the same nature and exists in the current form of sustainable development trying to answer a few key questions: What to do? What to opt for? What strategy to develop to follow?

\section{Methods}

The objective of this paper is to highlight the trends determined by the current health crisis. All these concepts take on a new meaning in the current pandemic context and the trend seems to be man's return to nature and villages, perhaps determined by home isolation as the central method imposed by most countries in the fight against Coronavirus The concept of sustainable development seems to answer these questions by approaching development with ecological caution, anticipating a realistic, harmonious, predictable development, in full agreement with the possibilities existing at a given time and place, emphasizing a development by own forces and resources, thus largely eliminating pollution and regional imbalances.

\section{Result and Discussion}

Sustainable development seeks to meet the fundamental requirements of present generations without taking the chance of future generations to meet them in turn; it focuses on meeting the requirements of rational consumption demands. At the same time, it is ecologically prudent because it seeks to include in the area of application and superior capitalization of resources and environmental conditions through an adequate management of nature. It thus satisfies the requirement of housing to be carried out in a space close to an economic activity in a natural environment and in buildings with minor impact on nature, by using any local resources and conditions to achieve, as far as possible, a recycling of resources. renewable in a process similar to a living organism - urban metabolism. 


\subsection{Ecological values of living in Romania}

Man, like all other species, has always tried to build his own habitat. Habitat is the place where a population lives naturally. Using a series of tools, man builds his own habitat, profoundly changing environmental factors, both inside and outside the territory of human settlements. Human habitat is defined as the relationship between the human population and the natural environment, on the one hand, and on the other hand by the dynamics of the relationships between human needs (both biological and psycho-social) and the tools of human action (technology as a result of the development of knowledge, institutional organization, result of the evolution of economic and social structures and cultural models, expression of the development of the life of a human community in a certain geographical area and in a defined historical period).

In this context, we can understand the home as an ecological reaction of the human species to the environment. The traditional home in Romania is characterized by deep ecological relations with the environment, illustrated by the way of living, and expressed by the spatial-functional organization, architectural expression, materials used (especially local) and last but not least, integration into the landscape (both formal as well as in the cultural landscape).

Industrial civilization, using the renewable resources of the environment (raw materials, energy, processing capacity of waste products, and even the use of space available for the development of human settlements), developed forms of settlements strongly structured in terms of space, technology, function, whose expression in the plan of the mass dwelling was the collective dwelling. The strong anthropization of the environment is a characteristic of most cities in Romania and living in collective housing has generated attitudes of alienation from natural values. The spatial concentration (necessary to ensure the utilities in the housing complexes), as well as the energy concentration and the waste in the same complexes, lead to significant negative environmental impacts, which are found in most collective housing neighborhoods in the country.

\subsubsection{The air in human settlements}

The main sources of air pollution are represented by the industry. The location of industrial units according to the principle of proximity to human settlements, was based on economic reasons (increasing the use of municipal networks and reducing travel to work). The result has often been, however, the proximity between industrial and residential areas, the latter being potentially exposed to the effects of pollution.

The substances resulting from the technological processes and then discharged into the environment are very varied: organic and inorganic powders, gases and vapors, soot, etc., but the amount of substances is different depending on the source of pollution. In addition to industry, anthropogenic sources of air pollution are also human activities in transport, agriculture and household.

Air pollution with sulfur oxides (having a share of $60 \%$ of total emissions) can lead to acid rain, both in the immediate vicinity of emission sources, but often at a great distance from these sources, with a regional or even cross-border.

\subsubsection{Car traffic}

Car traffic causes pollution caused by a mixture of over 150 different compounds. These pollutants can be grouped into several categories: inorganic gases (nitrogen oxides, sulfur dioxide, carbon monoxide, ozone), suspended dust, volatile compounds, exposure to these high-level substances affecting human health. Car, naval, rail and air transport emit a series 
of pollutants resulting from the combustion of fuels (gasoline or diesel): CO, NOX, unburned hydrocarbons, SO2, aldehydes. In addition to these, lead oxides also result in the combustion of gasoline added with tetraethyl lead and smoke, especially in the combustion of diesel.

The pollutants emitted have various influences on the environment and human health.

The greatest impact occurs in densely built-up areas (especially with high constructions) and with overcrowded traffic arteries, where the dispersion of pollutants is prevented due to the density of constructions, as well as in intersections.

Other sources of air pollution, especially in cities, are construction sites and concrete mixers, as well as power plants (CET). The latter are major sources of air pollution in urban areas (with $\mathrm{SO} 2, \mathrm{NOX}, \mathrm{CO} 2, \mathrm{CO}$, dust, smoke, ash), even the use of high chimneys amplifying the effects of remote pollution.

Diffuse combustion sources are the result of the operation of many plants, district or block thermal power plants, running on liquid or solid fuel.

Acidification is the result of emissions of acidifying substances (sulfur dioxide, nitrogen dioxide, nitrogen monoxide and ammonia). The degree of atmospheric dispersion produces effects at a great distance from the place of emission, which is added to the diffuse causes, but especially to the effects of car traffic. Other forms of air pollution are those with persistent organic pollutants, suspended dust and sedimentable dust.

\subsubsection{Noise pollution}

Several categories of noise act simultaneously in the urban environment: domestic and industrial noises, noises produced by the construction activity and by means of transport. Of these, the most important source of noise is urban traffic, which produces about $80 \%$ of noise pollution. The propagation of sounds is influenced by the source of noise, atmosphere, distance, obstacles encountered. The noise sources are: industry, cities, means of transport. They produce noises of different intensities and can be stationary or mobile. Polluted atmosphere, fog, attenuates noise. Obstacles also attenuate sound intensity, being used to reduce noise.

Noise pollution creates discomfort and is harmful in some urban areas, on traffic arteries and near noise sources.

Noise pollution also increases when certain industrial sections are spread over the entire territory of an urban settlement, especially when it is concentrated along the railways that cross the city. The degree of noise pollution depends on the type of production and the measures taken for noise pollution.

Other noises can be generated by specific sources (children's playgrounds, kindergartens, schools) that affect the immediate vicinity of housing complexes during the day, but also by large stadiums, although this is regular but very aggressive.

\subsubsection{Water pollution}

Water pollution is the alteration of the physical, chemical and biological qualities of water, produced directly or indirectly, naturally or anthropically. Polluted water becomes unfit for normal use. Pollution can occur:

- (permanently), as is the case of sewerage in a city, or waste from industry and discharged into water;

- discontinuous, at regular or irregular intervals of time;

- temporary (eg temporary colonies);

- accidentally, in case of damage. 
The quality of surface water in human settlements is affected by sewage discharges upstream. The main source of surface water pollution is industrial activity. Due to the malfunction of the pre-treatment plants, a large amount and diversity of chemical toxins of inorganic or organic nature are discharged into natural emissions.

Another source of water pollution is industrial and household waste that is not properly managed or unauthorized, which also allows the infiltration of hazardous substances caused by rainwater into either surface water or soil and groundwater. These effects are in addition to those generated by the overuse of pesticides and chemical fertilizers.

Surface water pollution, regardless of the cause, can induce major risks to the health of residents for nearby housing areas.

Groundwater, along with fresh surface water, is a source of water for mankind. Polluted surface water penetrates in layers to groundwater. They are already located in the impermeable layer, so there is no possibility of migration through rocks and consequently concentrate in pollutants. The level of pollution depends on the geological structure of the layers traversed and a number of hydrodynamic factors. At first, the layers retain pollutants, but over time they are entrained by water. As groundwater is often a source of drinking water, sanitary protection zones have been established.

\subsubsection{Soil pollution}

Soil pollution is any action that disrupts the normal functioning of the soil. Production activities have affected the soils over time, through: mining works, excavations, landfills, landslides, erosion, salinization, acidification, etc. Soil pollution is caused by deposition in the atmosphere, inadequate storage of household and industrial waste and residues, excessive chemicalization of land and agricultural crops, soil degradation caused by deforestation and lack of defense works, and lead pollution caused by heavy car traffic.

Industry heavily pollutes agricultural land. Urbanization also causes a decrease in agricultural areas by expanding cities. Lost land is often of the best quality for agriculture, as cities have formed in these areas.

According to the UN, $15.6 \%$ of the entire area is heavily degraded land, and $51.7 \%$ are moderately degraded, which is a quarter of the agricultural area.

\subsubsection{Urban waste}

Sanitation involves the disposal of urban solid waste (household, street, demolition, sludge from treatment plants) and includes a series of organized and coordinated activities: precollection, collection, transport, sorting, reuse, recycling, storage and / or destruction.

The annual amount of waste, especially in urban areas, can reach an average of $1000 \mathrm{Kg}$ / person, compared to European estimates at an average of $300-500 \mathrm{Kg}$ / person.

Before concluding, we believe that an assessment of the impact of policies, plans and programs on the environment can be done through the Strategic Environmental Assessment (SEA), with some researchers examining the use of SEA for sustainable urban development. They explored its opportunities to promote the principles of sustainability and highlighting both the potential of the SEA and its challenges for sustainable urban development [22].

Research examining the availability and characteristics of smart city applications in the field of sustainable urban development, addressing the specific sustainability challenges of green motor mobility, waste, air pollution, energy consumption, urban biodiversity and water management has reached an interesting finding; namely, that there is a very important research gap in how sustainability policy can be eliminated by technical requirements of smart cities to meet the specific needs and market niches of urban sustainability [23]. 
We also support the idea that the concepts and visions of sustainable development that emerged in the post-Brundtland era are explored in terms that lay the foundations for a common vision of sustainable urban development (SUD). A future direction of our research will follow the vision and methodology described for the SOUTH as a result of the activities of the BEQUEST international networks funded by the European Commission [24]. As a result, sustainable development based on the Brundtland Commission report and the processes of the UN Environment and Development Committee implies sustainable urban development that requires much more ambitious policies than those proposed today to limit energy consumption, reduce pollution and protect areas [25].

\section{Conclusions}

We embrace the UN conclusions that the current pandemic has shown that society is capable of rapid transformation and adaptation and an inclusive urban future is needed for resilience. Transforming cities globally for future resilience, inclusion, ecological and economic sustainability is becoming urgent as the pandemic has exacerbated existing inequalities. In fact, investing in inclusive cities means investing in inclusive countries where reducing urban inequalities becomes a cornerstone to better prepare for future shocks and crises and ultimately lead to prosperity. We also support the general view that the pandemic has accelerated the digitization of service delivery, including telemedicine, elearning, remote work and the application of technology to various aspects of crisis prevention and management so that digitization opportunities in government, trade, labor and Key economic and educational issues have diversified. COVID19 has accelerated progress in almost all economic areas and required the application of digital solutions and innovation for the planning, management and governance of cities and urban infrastructure in particular. Perhaps the most important positive effect of the endemic would be that economic recovery could lead to a deep green transformation in which well-designed stimulus measures that support a green economic recovery could bring long-term economic benefits and align urban planning and development to health. Human and planetary is essential to avoid ecological imbalances, reduce the risk of exposure to new pathogens and the emergence of new diseases. UN reports show that broadly targeting cities in a course towards sustainability, accessibility, innovation, equality and respect for human rights are policy recommendations that can be adapted to local contexts - not just to recognize the strengths and unique challenges of different cities and even neighborhoods in cities, but also to ensure respect for their unique character and culture.

\section{References}

1. Haughton, G. (1997). Developing sustainable urban development models. Cities, 14(4), 189-195.

2. Rydin, Y. (2012). Governing for sustainable urban development. Earthscan.

3. Barles, S. (2010). Society, energy and materials: the contribution of urban metabolism studies to sustainable urban development issues. Journal of environmental planning and management, 53(4), 439-455.

4. Yigitcanlar, T., \& Teriman, S. (2015). Rethinking sustainable urban development: towards an integrated planning and development process. International Journal of Environmental Science and Technology, 12(1), 341-352.

5. Drakakis-Smith, D. (1995). Third world cities: sustainable urban development, 1. Urban studies, 32(4-5), 659-677. 
6. Rabinovitch, J. (1992). Curitiba: towards sustainable urban development. Environment and Urbanization, 4(2), 62-73.

7. Alpopi, C., Burlacu, S., \& Ioviţu, M. (2018). Procesul de globalizare şi politicile ecologice. In Competitivitatea şi Inovarea în Economia Cunoaşterii, 2, 317-324.

8. Bran, F., Rădulescu, C. V., Bodislav, D. A., \& Burlacu, S. (2020). Environmental risks in the context of globalization. Economic Convergence in European Union, 350-356.

9. Androniceanu, A., Burlacu, S., Drăgulănescu, I. V., \& Nicolae, E. E. (2017, May). New trends of businesses digitalization in Romania and the behaviour young consumers. In BASIQ International Conference: New Trends in Sustainable Business and Consumption, Graz, 31, 27-35.

10. Bodislav, D. A., Buzoianu, O. A. C., Burlacu, S., \& Rădulescu, C. V. (2020). Analysis of companies in Romania from the perspective of risk perception and the management needs thereof. Economic Convergence in European Union, 341-349.

11. Bodislav, D. A., Radulescu, C. V., Bran, F., \& Burlacu, S. (2020). Public policy in the areas of environment and energy. New Trends in Sustainable Business and Consumption, 228-235.

12. Bran, F., Burlacu, S., \& Alpopi, C. (2018). Urban Transport of Passengers in Large Urban Agglomerations and Sustainable Development. Experience of Bucharest Municipality in Romania. European Journal of Sustainable Development, 7(3), 265273.

13. Bran, F.., Alpopi, C., \& Burlacu, S. (2018). Territorial Development-Disparities between the Developed and the least Developed Areas of Romania. LUMEN Proceedings, 6(1), 146-155.

14. Burlacu, S., Alpopi, C., Mitrită, M., \& Popescu, M. L. (2019). Sustainable eGovernance and Human Resource Development. European Journal of Sustainable Development, 8(5), 16.

15. Burlacu, S., Gavrilă, A., Popescu, I. M., Gombos, S. P., \& Vasilache, P. C. (2020). Theories and Models of Functional Zoning in Urban Space. Revista de Management Comparat International, 21(1), 44-53.

16. Burlacu, S., Alpopi, C., \& Popescu, M. L. (2018). Omul și degradarea mediului natural. Efecte distructive. In Competitivitatea şi Inovarea în Economia Cunoaşterii, $1,159-165$.

17. Caffe, M. (1987). Locuinta contemporana: Probleme si puncte de vedere, Editura Tehnica.

18. Derer P.-Locuirea urbană, Editura Tehnică, Bucureşti, 1985

19. Ionita, F., Ursacescu, M., \& Burlacu, S. (2009). Public Services as Poles of Regional Competitiveness in Sustainable development. Revista de Management Comparat International/Review of International Comparative Management, 10(3), 552-565.

20. Ionita, F., Burlacu, S., \& Gaidargi, A. (2009). Modern approaches of the management of alternative trade systems. Rev. Int. Comparative Manage, 51, 473-480.

21. Sârbu, C. N. (2006). Locuirea în România: o abordare-cadru. Editura Universitară" Ion Mincu".

22. Shepherd, A., \& Ortolano, L. (1996). Strategic environmental assessment for sustainable urban development. Environmental Impact Assessment Review, 16(4-6), 321-335. 
23. Angelidou, M., Psaltoglou, A., Komninos, N., Kakderi, C., Tsarchopoulos, P., \& Panori, A. (2018). Enhancing sustainable urban development through smart city applications. Journal of Science and Technology Policy Management.

24. Bentivegna, V., Curwell, S., Deakin, M., Lombardi, P., Mitchell, G., \& Nijkamp, P. (2002). A vision and methodology for integrated sustainable urban development: BEQUEST. Building Research \& Information, 30(2), 83-94.

25. Naess, P. (2001). Urban planning and sustainable development. European Planning Studies, 9(4), 503-524. 